TI 2006-063/2

Tinbergen Institute Discussion Paper

\title{
A New Explanatory Model For Policy Analysis And Evaluation
}

\author{
Marije Schouwstra \\ Michael Ellman
}




\section{Tinbergen Institute}

The Tinbergen Institute is the institute for economic research of the Erasmus Universiteit Rotterdam, Universiteit van Amsterdam, and Vrije Universiteit Amsterdam.

Tinbergen Institute Amsterdam

Roetersstraat 31

1018 WB Amsterdam

The Netherlands

Tel.: $\quad+31(0) 205513500$

Fax: $\quad+31(0) 205513555$

Tinbergen Institute Rotterdam

Burg. Oudlaan 50

3062 PA Rotterdam

The Netherlands

Tel.: $\quad+31(0) 104088900$

Fax: $\quad+31(0) 104089031$

Most TI discussion papers can be downloaded at http:/ /www.tinbergen.nl. 


\title{
A new explanatory model for policy analysis and evaluation
}

\begin{abstract}
This model of policy evaluation has been developed to identify factors that cause policy outcomes to diverge from the intended results. In this model the explanatory factors may be inherent to the conceptual and institutional framework to which policy makers adhere, or they may be 'real world' factors such as badly-defined performance indicators or cyclical economic problems. This model can be used by scholars for analyzing and evaluating government policies and the policies of international organizations and by policy makers to improve their policies. The model can also be used for cross-country comparisons to establish why a certain policy works in one country or situation and why it does not work in another country or situation.
\end{abstract}

\section{Introduction}

Designing 'correct' policies has been a focus point of national governments and international organizations over the past decade. This focus has culminated in an extensive literature on, and a theorizing of, the policy process. At the governmental level it resulted in white papers, mission statements and strategic plans, and on the project level in literature on strategies, design and models (see also Mosse 2004, pp. 639-640). In line with the increasing interest in designing 'correct' policies, policy evaluation too has received more attention as well. This has resulted in the establishment and reorganization of evaluation units and departments at ministries and international organizations ${ }^{1}$. On the theoretical level, policy makers may acknowledge that evaluations should be an integral part of the policy-making process. In practice, however, using the outcome of evaluations in redefining policies or designing new policies is not yet common in many countries and organizations even though the foundations for doing so have been created. The focus of policy makers is still on the future and on new beginnings, and not so much on analysis and learning from the past (Mosse, 2004, pp. 640).

Evaluation is not an integral part of the policy cycle in most countries and organizations. In part, this is because separate evaluation units and departments have been created, thus separating policy design and evaluation, with the unfortunate result that policy makers no longer deem it their task to evaluate. And, in part, this is also due to power politics. Some individuals in a position of power and responsibility prefer to play their cards close to their chest so as to protect their position and their funds. They prefer not to evaluate and not to be transparent. But that is a political problem which has to be solved on the political stage, and therefore this article will not be concerned with that phenomenon. There are, however, other reasons why more can be learned from evaluations than is the case at present.

First of all, the resources that are spent on evaluation are mainly devoted to monitoring project implementation and to producing immediate outputs, but very few resources are devoted to the systematic assessment of whether policies, programmes, and projects achieve their intended impacts and benefits for the target populations (Bamberger, 2000, p. 96). This being so, a shift of focus towards evaluating intended outcomes would be beneficial. A shift of focus is, however, only possible if good models to evaluate are at hand.

\footnotetext{
${ }^{1}$ The IMF established its Independent Evaluation Office (IEO) in July 2001 (see www.imf.org), the World Bank reorganized its Operations Evaluation Department in 1997 (see E. McAllister, 'OED Renewal: Participation. Partnership, and Results’, in P.G. Grasso, S.S. Wasty, R.V. Weaving, eds., World Bank Operations Evaluation Department, The First 30 Years, p.78), and the World Bank and the UNDP established the Institutional Development Evaluation Association (IDEAS) in 2003 (see www.worldbank.org and www.ideas-int.org).
} 


\section{Evaluating policies}

An evaluation is only as useful as the model that has been used for that evaluation. For example, when econometric techniques are used to evaluate policies, but the variables are not well specified or too many parameters have to be estimated, then the question arises whether the outcome of the model really represents and is connected to the real-world outcome of a policy. The same is valid for other models that can be used for policy evaluation. If a variable is not in a model, it will not be evaluated. If too many parameters have to be estimated, or there are too many assumptions underlying a model, the question again arises whether the outcomes of the model are representative of the real-world outcomes of a policy.

Many models of policy evaluation that are being used have a too narrow scope. They only focus on accountability and the immediate goal or objective of the policy to be evaluated. For instance, if the objective of the macroeconomic policy of a Ministry of Finance is to reduce inflation and to stimulate economic growth, the evaluation will look primarily into the performance indicators 'level of inflation' and 'economic growth'. Side effects such as the social or distributional effects of such policies are usually not evaluated or reported upon. If a government tries to reduce unemployment with certain measures, and the performance indicator is the 'level of unemployment' then it is easy to conclude that the measures were beneficial if, after a year, unemployment has decreased. If, however, the economy has been growing during that time, it is certain that will have had a beneficial influence on the unemployment rate as well, and it will be hard to establish what has actually caused the decline in unemployment. Of course, most models are somewhat better-specified and have overcome such inaccuracy, but this unemployment example captures two of the most fundamental problems of evaluating policies in the real world very well.

First, policy evaluation models do not and often cannot make explicit whether it is really the policies being evaluated that have caused the observed effects. The models do not try to establish how and why a policy brings about the observed outcomes. They look at predetermined variables and - preferably quantified - performance indicators and have assumptions on how a policy brings about the observed results.

Second, many models specify only a limited number of variables on which a policy or programme has influence. Only the predetermined performance indicators are covered and not other variables, performances, or consequences of a policy. Both shortcomings are very understandable and difficult to prevent completely, as it is very hard to establish in the real world what is cause, what is effect, what causes which effect (the problem of spuriousness ${ }^{2}$ is very real), and how does it cause that effect? And what exactly are all the variables and all the consequences of a policy? It would be a very extensive task to establish this. Furthermore, with regard to the power-political aspects of policy making, it may often not be desirable for political or policy-making purposes to look into all effects of a policy, even though it is known or likely that, for instance, side effects exist.

In this article, a new explanatory model of policy evaluation will be presented with the aim of broadening the scope of policy evaluations in order to capture the most important factors that generally influence the outcome of a policy. It is a model that can be used by academics and evaluators to evaluate policies and which policy makers can use as an instrument to improve the effectiveness of their policies. It seeks to encompass all categories of factors which a policy maker can, and has to, take into account when making policies. It is a rational model of policy evaluation which incorporates - besides the usual elements of a policy-making cycle -

\footnotetext{
${ }^{2}$ Spuriousness is the phenomenon whereby two variables are observed and a person concludes there is a causal relation between the two, whereas actually an unseen third variable causes them both. See W. Lawrence Neumann, Basics of Social Research, Boston, 2004, pp. 98-99. In other literature it is also referred to as a hidden variable.
} 
institutional factors and conceptual or normative factors (i.e. incremental factors) ${ }^{3}$. The model furthermore stresses the importance of evaluation as an integral part of the continuous and dynamic cycle of policy making.

\section{The Geelhoed-Schouwstra framework}

The basis of the model is a simple but effective framework of policy analysis that has been developed as a corollary of the project $\mathrm{VBTB}^{4}$ of the Dutch Ministry of Finance (2002) - a project to improve the quality and speed of financial accounting ${ }^{5}$ - and can be used for analysing local and national policies and programmes. The Geelhoed-Schouwstra framework is a schematic representation of the policy process as depicted in VBTB, and the framework can easily be combined with other methods and representations of policy and project planning and evaluation. In this framework the policy-making cycle consists of six fundamental elements or steps (A - F) (see Figure 1).

\section{A. Goal}

The first step of defining programmes and making policies is to define the strategic or tactical goal $^{6}$. This goal is always defined in rather general terms and the accompanying performance indicators are equally general. Thus, a Secretary of State who wants to combat unemployment in order to increase social stability defines the goal as: 'increase social stability by a reduction of unemployment', and the accompanying performance indicator on this level may be 'the amount by which the level of unemployment has been reduced', either as an absolute number or as a percentage. A quantitative performance indicator of increasing social stability depends very much on the country concerned and could be a decrease in the number of demonstrations or riots but could equally well be a decrease in inequality in income between various groups in society.

\section{B. Objective(s)}

The objective or objectives are the operationalized strategic or tactical goals. They are directly derived from the goal but are more specific. The accompanying performance indicators are more specific as well. The objectives provide the actual starting point for looking at methods or instruments that can be used to reach the goal.

\footnotetext{
${ }^{3}$ For various approaches to decision-making and rational models versus incremental models, see Chapter 11, 'Decision-Making Processes’ of R.L. Daft, Organization Theory and Design, seventh edition, Cincinnati, Ohio, 2001, pp. 398-438.

${ }^{4}$ VBTB stands for 'Policy Budgets and Policy Accountability' (in Dutch: 'Van Beleidsbegroting Tot Beleidsverantwoording'). The aim of VBTB was to accelerate the process of financial accounting and to improve its quality at the request of the Lower House of the Dutch Parliament. A new style of budgeting was announced, in which policy and what it was intended to achieve was taken as its point of departure and not the funding. The central questions in the Dutch budgeting system now are: What do we want to achieve? What will we do to achieve it? What will we allow it to cost? See Interministerial Consultations for Financial and Economic Affairs, Policy Budgets and Policy Accountability: Evaluation, Lessons from Practice, December 2004, paragraph 1.1, and Ministerie van Financiën, VBTB, Van Beleidsbegroting tot Beleidsverantwoording, Den Haag, May 2002.

${ }^{5}$ See Interministerial Consultations for Financial and Economic Affairs, Policy Budgets and Policy Accountability: Evaluation, Lessons from Practice, December 2004.

${ }^{6}$ Goals are often set down in the mission statement of an organization.
} 
Figure 1: Basic framework - the six steps of the policy-making cycle ${ }^{1}$

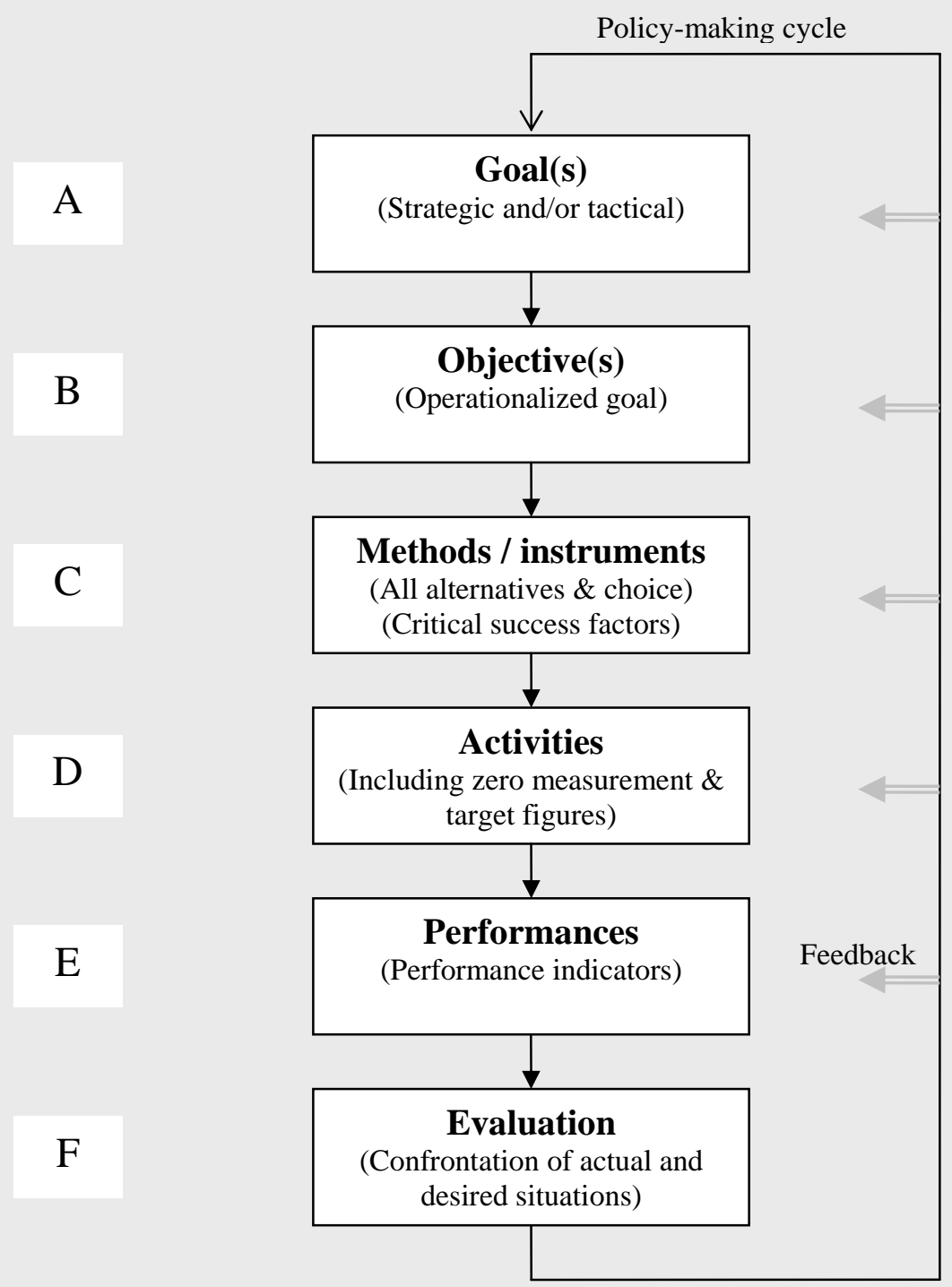

\section{Methods / instruments}

The methods or instruments are the means by which the objectives should be realised, and hence the strategic or tactical goal(s). In general, many policy makers tend to be very focussed on instruments and methods or even on specific activities and do not really consider all alternative instruments or methods to reach an objective in a systematic and constructive way. Ideally, a policy maker should provide an overview of all alternative methods and/or instruments, together with the pros and cons of each alternative, and make a well-reasoned choice from among the listed alternatives ${ }^{7}$. Such an overview would not only make decision making more rational and

\footnotetext{
${ }^{7}$ Unlike the decision-making process in business, in public administration there is generally speaking time to make a well-informed decision on the basis of a multi-focused and maximizing decision-making process. Daft (2001, p. 408) defines multi-focused decision makers as 'wanting to develop a variety of options and related pros and cons before deciding' (as contrasted to uni-focused decision makers who 'look at the
} 
transparent and would increase accountability, but it would also provide evaluators with the information they need to make a good evaluation. In particular, the way in which policy makers think the chosen instrument or method will bring about a certain effect should be included in an overview, so as to provide evaluators with the means to assess that method or instrument.

Before choosing a method and/or instrument, it is important to identify the critical success factors. Critical success factors create limiting conditions for methods, instruments and activities and play a decisive role in achieving the defined goals (strategy) and related objectives ${ }^{8}$. Critical success factors are scarce resources that are potential bottlenecks in policy implementation. Because of their scarcity, critical success factors may exert a great influence on a policy or programme and its outcome. It is important to list not only the limiting factors and potential bottlenecks that can be influenced by a policy maker and his or her superiors but also those that cannot be influenced. Think, for instance, of a policy to combat unemployment. However good such a policy is, if there is an economic recession, unemployment will rise. Such factors may be of overriding importance when making a choice from amongst the listed alternatives. For both transparency and evaluations, it is important that the motives for choosing a specific alternative are well recorded and that such a record includes all the factors that influenced the decision (though it is probably not realistic to expect that power political motives are included in such a record).

\section{Activities}

The level of activities is the most explicit level in the policy-making cycle. On this level, the specific activities that should lead to realizing the goals and objectives are defined and implemented. It is important that the activities are defined so explicitly that they really can be implemented. The performance indicators of activities are equally explicit. Performance indicators need not just be about the outcome or result of activities. For monitoring purposes, some may also refer to input, throughput and output of activities. However, it should not be exclusively input, throughput and output; ultimately, it is the results that count and should be evaluated.

For all indicators a zero-measurement ${ }^{9}$ needs to be established, so that when activities are being evaluated after a certain period, the performances can be compared with situation at the beginning of the implementation of the policy or programme and the effectiveness and efficiency of the policy or programme can then be established. Target measures should be defined as well, with which the actual performances should be compared in order to determine whether the progress of a policy or programme is as was planned ${ }^{10}$.

\section{E. $\quad$ Performance}

The performance of a policy or programme is measured by predetermined performance indicators. Every step in the policy-making cycle has its own performance indicators, which range from very general for the goal(s) to very specific for the activities. Performance indicators are necessary not only to evaluate the outcome of a policy or programme but are needed for

problem with the idea of coming up with a single solution') and defines a manager who is a maximizer as a person who 'wants as much relevant information as possible before making a decision' (as contrasted with a satisficer; a person 'who wants just enough information to get on with the decision').

${ }^{8}$ See R. van Oirsouw, J. Spaanderman and H. de Vries, Informatie economie, Meppel, 1993, p. 164, and J. Geelhoed, Control Deficiencies in the Dutch Health Care Sector, An analysis of the planning and control cycle in hospitals and the Dutch Ministry of Health and the relationship between them, Febodruk, Enschede, 2005, pp. 31, 33.

${ }^{9}$ A zero-measurement is the initial measurement at the time of designing the policies.

${ }^{10}$ Note that for each separate activity this framework can be used again. What is the goal and objective of the activity? What instrument or method will be used? How is it supposed to work? What results should be brought about? Etcetera. 
planning and control as well. Managers need performance indicators to be able to steer the process and to secure efficient processes and performances. Thus performance indicators can refer to input, process, throughput, and output ${ }^{11}$ as well.

The definition of performance indicators may have far-reaching consequences for a policy or programme, as performance indicators have the capacity to shape a policy or programme and its outcome. If implementers know they will be held accountable for the success of the policy or programme and this success is measured only with reference to certain performance indicators, the implementers will tend to focus on performing well on those indicators only. The performance indicators start having a life of their own and the real goal and objectives of the programme or policy easily become lost. Examples of this phenomenon are plentiful and easily found. To give an example, in the Netherlands pupils have to do a series of tests at the end of primary school to determine their level of learning and subsequently to what secondary schools they can go. Nearly all schools participate in these tests. The scores of the pupils on these tests are now made public and are being used to compare the performances of the various schools. To be evaluated more positively, some schools start training their pupils only to the tests, instead of teaching them the regular curriculum ${ }^{12}$. Instead of an increased focus of schools on the development and performance of children and of improving school performances, in fact the opposite effect is achieved by the use of this performance indicator ${ }^{13}$. Thus the formulation - and correct use - of performance indicators is crucial to the successful implementation of a policy.

Defining good performance indicators is one of the most complicated parts of policy making. A common mistake is to use activities as indicators of performance. Holding workshops or conferences is, for instance, commonly used as a performance indicator ${ }^{14}$ but those are obviously activities and are only measures of output. Activities are not an end in themselves, but are done to bring about an effect. And the effect is what an evaluator wants to measure with a performance indicator. He or she wants to know whether the intended results have been brought about or not. The manager wants to know about output for planning and control, but a policy maker, a secretary of state, or the general public want to know whether the objectives and goals of a policy have been achieved, not merely whether activities have taken place. They want to be informed about the impact of the activity and it is that which should be captured in the performance indicator.

To capture all the crucial elements of a policy in indicators without overburdening the implementers of a policy with meaningless or useless indicators is difficult. Too many indicators are an administrative burden for the implementers and cause the cost of a policy to rise, as

\footnotetext{
${ }^{11}$ Some authors make a distinction between monitoring and evaluation. Bamberger defines monitoring activities as "activities that are conducted during project or programme implementation to assess the efficiency and effectiveness with which inputs are used to achieve intended outputs". He defines evaluation activities as "activities to assess the extent to which projects or programmes have achieved their intended objectives and have produced their intended changes and benefits in the target populations”. See M. Bamberger, 'The Evaluation of International Development Programs: A View from the Front', American Journal of Evaluation, Vol. 21, No. 1, 2000, p. 96.

${ }^{12}$ Other measures to increase scores are used by the schools as well: for instance preventing poorly performing children from participating in the tests, or having them do the tests but keeping their scores back so that it will not influence the total score of the school negatively. In some of the large cities, as many as $25 \%$ to $33 \%$ of the pupils do not participate in these tests.

${ }^{13}$ This is by no means a new phenomenon. As far back as the end of the 1950s, the problem was identified in the scientific literature. See, amongst others, A. Nove, 'The problem of success indicators in Soviet industry', Economica, 1958; and C.J. Hitch \& R. N. McKear, The economics of defence in the nuclear age, 1960, pp. 158-181.

${ }^{14}$ See, amongst others, the analysis of the programme Andere overheid of the Dutch government in J. Geelhoed and M. Schouwstra, "Krachtige overheid begint met heldere taal', Openbaar Bestuur, Nr. 8, August 2005, p. 5.
} 
gathering data has a price. Therefore, from a pragmatic point of view, the number of indicators has to be as limited as possible. Only those that are really necessary to establish the effectiveness and efficiency of a policy ('Has the objective or goal been reached?') should be defined. Those indicators should be supplemented by a minimum of indicators that are necessary for planning and control. Such a minimum of performance indicators can only be realized if policy makers really have a very good insight into the workings of a policy, and if they are very good at defining indicators. On the other hand, when too few indicators are formulated, it means that a manager does not have the instruments to control the processes, and that the authorities that commissioned the implementation of a policy do not have the means to check the efficiency and effectiveness of that policy or programme, and nor can they hold the implementers accountable for the results that have, or have not, been achieved when the desired results have not been defined clearly.

Performance indicators can both be quantitative and qualitative. Nowadays, there is a strong preference for quantitative indicators as those are more easily measurable and thus easier to work with than qualitative indicators. Comparisons are much easier with quantitative data: the result of a policy or programme presented in a graph or as numbers in a table looks much more solid than just a description of various aspects of performance. With regard to accountability and finance, the advantages of quantitative indicators are also obvious. However, this stress on, and use of, quantitative performance indicators does have its downside.

A serious disadvantage of the preference for, and nearly exclusive use of, quantitative performance indicators is that quantitative indicators only capture a very specific part of a policy or programme when it is being implemented in the real world. Many, or even most, aspects of social processes may, for instance, be very hard to capture in quantitative indicators. Capturing increases in quality or monitoring the process need not always be, but often is, difficult to express in quantitative indicators. When using quantitative indicators only, it is quite possible that a large part of a policy does not get evaluated, and thus there is considerable risk that it will not be implemented as well.

\section{F. Evaluation}

Evaluations have a purpose. For those who commissioned a policy, evaluations generate the information to judge whether the goals and objectives that have been set have been reached, and whether this has been done effectively ${ }^{15}$ and efficiently ${ }^{16}$. For planning and control, evaluations generate the information to control and steer the processes, which may lead to a better achievement of the objectives and goals that have been set. In the policy-making process, evaluation is necessary to improve upon policies and programmes by giving feedback at every step and on every element in the policy process from the first beginnings of the policy design to policy implementation. Evaluation should be an integral part of the policy-making cycle, being repeated at regular intervals in time. That is a crucial feature necessary to make the policy process a learning process that leads to a structural improvement of policies and programmes.

How an evaluation is done depends on the specific purpose of the evaluation, the audience for that evaluation ${ }^{17}$, and the evaluators themselves. Is the audience the authorities that commissioned the policy or programme, the manager who wants to increase the effectiveness of a policy measure, or the taxpayers? Are the evaluators academics trying to find out whether the

\footnotetext{
${ }^{15}$ Daft (2001, p.64) defines organizational effectiveness as 'the degree to which an organization realizes its goals.' 'Effectiveness evaluates the extent to which multiple goals - whether official or operative - are attained.'

${ }^{16}$ Daft (2001, p.64) defines efficiency as 'a more limited concept that pertains to the internal workings of the organization. Organizational efficiency is the amount of resources used to produce a unit of output.' 'If one organization can achieve a given production level with fewer resources than another organization it would be described as more efficient.'

${ }^{17}$ See P.G. Grasso (2003) on the importance of identifying the (multiple) audiences of an evaluation.
} 
assumptions and theories upon which the policies are based are correct? Or, is it the evaluation unit of a ministry or organization that establishes whether the gaols and objectives of a policy have been achieved? Is it an accountant who wants to establish whether the expenses of a policy were legitimate, or is it the policy makers themselves who want to improve upon their policymaking process? Before starting an evaluation it is necessary to establish what the purpose of the evaluation is, who the audience is, who should perform the evaluation and how it should be done.

The fact that evaluations should be an integral part of the continuous policy-making cycle and should be done at regular intervals by the policy makers themselves does not diminish the importance of separate evaluation units within ministries and organizations or independent evaluations done by outsiders. All those evaluations have their own function and can reinforce the learning process within the policy-making cycle and within organizations. Furthermore, outside evaluations are necessary for accountability and for legitimizing policies to the general public. If policy makers were only to evaluate themselves and there were no 'independent ${ }^{18}$ evaluations, the learning effect of the evaluations would almost certainly be less than is the case with additional 'independent' evaluations. Independent evaluations not only capture other shortcomings than policy makers would do themselves, but they also provide an incentive to policy makers to make their own evaluations well and honestly and take their own outcome seriously. Having only 'independent' evaluations would also diminish the learning effect, as policy makers are in general not very concerned with learning from the past if it is not built into the policy-making process and the evaluators are situated at a different location. The time-lag also works against learning from independent evaluators: by the time the 'independent' evaluation comes, policy makers are already occupied with (designing) a new policy.

In general the goal of an evaluation is to establish whether the policy-making process has been 'correct', whether a policy has been implemented as was planned, whether the goals and objectives of the policy or programme have been achieved or not, whether the budgets have not been exceeded, and whether - and, if so, how - the policy or programme can be improved. The most important features of the evaluation should be that feedback is given on every element of the policy-making process, and that with the help of this feedback policies can be redesigned and improved.

\section{The extended policy framework}

What this basic framework of policy evaluation does is to establish what the goals and objectives of a certain policy are, what the instruments and methods are that will be used, what activities will be undertaken, and how the intended results of that policy will be measured. Using this framework means that policies will be much more goal-oriented (and less instrument-, activityand/or fund-oriented $)^{19}$. What this framework does not do, however, is to establish the way in which the policy is supposed to bring about the supposed effects. Nor does it establish the side effects of a policy. Medical practitioners use the proverb: 'If medicines do not have side effects, neither do they have any effects'. With regard to policies, one can transform this saying into: 'Policies that have effects will have unintended side effects as well'. But whatever is not in the model will not be evaluated. The framework as described above does in principle provide scope for defining performance indicators of side effects, but policy makers will not necessarily do this when using the framework.

\footnotetext{
${ }^{18}$ In this paragraph I refer to the independent evaluation units of organizations as being independent as well, even though such units or departments are not truly independent.

${ }^{19}$ For the adaption and application of this framework of analysis to the cycle of planning and control in the health sector, see J. Geelhoed, Control Deficiencies in the Dutch Health Care Sector, An analysis of the planning and control cycle in hospitals and the Dutch Ministry of Health and the relationship between them, Febodruk, Enschede, 2005.
} 


\section{The conceptual framework}

Improving upon this framework means in the first place adding factors that indicate how policies will bring about the desired effects. One important factor concerns the conceptual or normative framework of policy makers. Underlying the goals, objectives, instruments, methods and activities chosen, policy makers have assumptions and theories on how the policy is supposed to bring about the intended effects, and hence achieve the objectives and goals. To clarify those, it is necessary to add an additional layer to the framework in which the definitions, assumptions and theories are specified ${ }^{20}$. For an evaluation such clarifications are important as otherwise it would be impossible to trace why the actual effects of a policy are different from the intended or assumed effects and thus - depending on the causes of the different outcome - it would not be possible to improve policies.

The conceptual framework influences all elements or steps of the policy-making cycle (see Figure 2).

Figure 2: An extension of the basic framework: the conceptual framework and its constituent elements

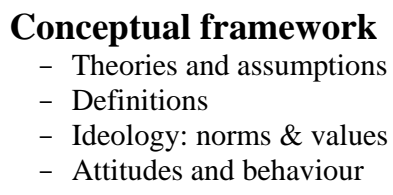

The conceptual framework in international policies and programmes

In international policies ${ }^{21}$, the conceptual framework on which a policy or programme is based is very important, as people with different backgrounds tend to have different views on a specific policy or programme. When a certain successful policy is being transferred to, and implemented in, a new country or organization, the intended effects of that policy may well be very different because of those differences. Even when the same words are being used, it is quite possible that people adhere to their own different definitions of central or main concepts of a policy. To give an example, the international financial institutions (IFI) advised the former communist countries to privatize all state-owned companies in order to establish a market economy as fast as possible. But what is privatization? Is a privatized company a formerly state-owned entity that is entirely in private hands, or does an entity that is partly in private hands qualify as privatized as well? Does it depend on the number of shares that are owned by non-state entities? And what are non-state entities? If the management of an enterprise is privatized but not the enterprise itself, ${ }^{22}$ is that regarded as a privatized entity or not? In all these cases, people may use the same word, but the concept and definition of that word is different in all these cases, thus causing a Babel-like confusion.

\footnotetext{
${ }^{20}$ This article only identifies categories of factors that have to be taken into account in an evaluation of public policies and programmes. It is not concerned with how to reconstruct the conceptual framework. See F.L. Leeuw (2003, 1991) and P.J. Rogers (2000) for this. In Leeuw’s terminology the basic framework aims at reconstructing the programme logic and this part of the extended framework aims at reconstructing the programme theory.

${ }^{21}$ When the term 'international policies' is used in this text, it can also be interpreted as 'international programmes' or 'international projects'.

${ }^{22}$ This is the case with some hospitals in Mongolia.
} 
The framework should therefore be extended with what is called here the conceptual framework ${ }^{23}$. It refers to the ideology, the norms and values to which people adhere, to the theories and assumptions upon which they base their policies and programmes, the definitions they use, and their attitudes and behaviour. The conceptual or normative framework is influenced by culture, geographical characteristics and history. Both the individual history of a person and the history of the region or country where a person lives, or has lived, shape his or her conceptual framework. Thus, a person who has grown up under the Communist system will have a different view of the world as compared with one who has grown up in one of the capitalist countries. A person who has been trained and schooled in a Buddhist monastery will have a different perception of the world from a person who is the product of the Western school system ${ }^{24}$. The type of study a person has followed also has a lot of influence on his or her perception of the world. An economist will have a different view of the rationality of human beings than a psychologist. Realizing those differences and the effect that those differences may have on programmes and policies means being able to anticipate them. And being able to anticipate them in policies and programmes, means realizing more successful policies and programmes.

Thus, in order to find out why the outcomes of policies and programmes diverge from the intended or assumed outcomes means that one should extend the framework of policy analysis with the conceptual framework and with the elements history, culture and geography as these may greatly influence the conceptual framework. This extended framework can schematically be represented as follows (see Figure 3):

Figure 3: An extension of the basic framework: the conceptual framework influenced by the elements history, culture and geography

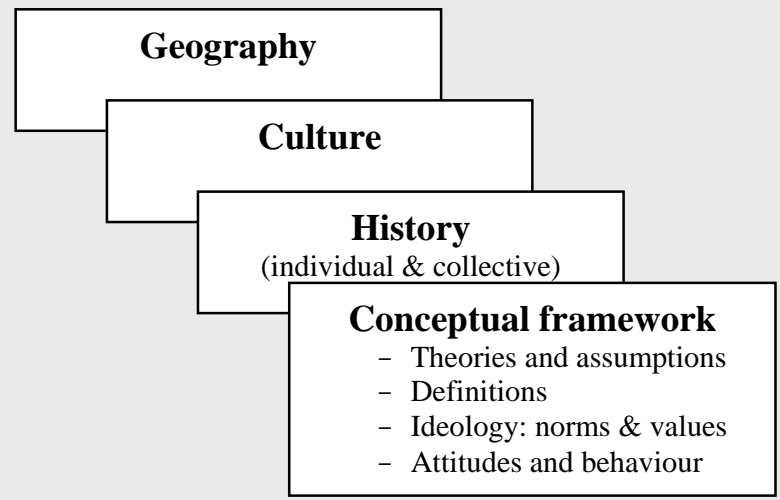

The importance of the conceptual framework was demonstrated in transition countries at the beginning of the 1990s, when advisors of the International Financial Institutions gave their advice from a neo-liberal economic (or capitalist) background, whereas the policy makers in transition countries had a communist background. They had a completely different idea and understanding of how an economy works and what the role of the state should be in an economy. In such a situation, even if policies and programmes are faithfully implemented exactly according to the framework as described above, policies will not work as designed by the advisors. It is the implicit assumptions that are inherent to one's conceptual framework (the 'internal assumptions')

\footnotetext{
${ }^{23}$ Economists often refer to it as the set of informal institutions.

${ }^{24}$ See, amongst others, W. Prayukvong, 'A Buddhist economic approach to the development of community enterprises: a case study from Southern Thailand', Cambridge Journal of Economics, 2005, 29, pp. 11711185.
} 
that can easily cause problems in international programmes, as they are usually not made explicit - and thus are not taken into account - in a policy or programme design.

\section{The institutional framework}

The extension of the framework of policy analysis with a conceptual framework is, however, not sufficient to establish all the differences between the expected and the real outcomes of policies and programmes. The institutional framework is at least as important in explaining such deviating outcomes as the conceptual framework.

The institutional framework refers to the political, social and economic setting in which a policy has to be implemented. It refers to the institutions that exist in a country and the legal setting of that country. It refers to all stakeholders of a policy or programme. It comprises all structures that exist in a country which are important to, and exert an influence on, a policy. Economists would refer to it as all formal institutions, but the concept of institutional framework is broader as it also comprises the stakeholders - whether individuals or organizations and whether with overt or tacit interests ${ }^{25}$ - of a policy or project. It is not the intention to go into too much detail here on the institutional framework as, for each analysis or evaluation, the framework has to be adapted to the particular programme or policy that is being analysed and the categories need to be refined to capture the essentials of that programme or policy ${ }^{26}$. Those categories can be represented as follows (see Figure 4):

Figure 4: An extension of the basic framework: the institutional framework and its constituting elements

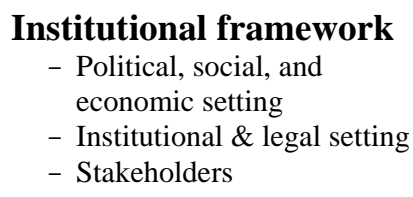

The institutional framework in national policies and programmes

When implementing a national policy or programme, first, it is worthwhile to analyse the institutional framework thoroughly, especially in connection with the theories, assumptions and definitions underlying a specific policy or programme. If the assumptions with regard to any of the elements of the institutional framework are wrong, one can expect a different policy outcome from that intended. Thus it is important to establish what requirements should be fulfilled with regard to the institutional framework in order to be able to implement a policy successfully, and, if requirements are not fulfilled, what influence that will have on the outcomes of the policy when it is being implemented. To give an example, privatization policies are usually based on the premise of fully competitive markets. When markets are not fully competitive this has a strong

\footnotetext{
${ }^{25}$ Power political motives - or struggles - of key stakeholders may, for instance, greatly influence the choices being made in and the outcomes of policies and programmes. Power-political struggles may work against a rational decision-making process and may lead to suboptimal policy choices.

${ }^{26}$ For an example of the importance of the institutional framework for the outcome of policies and how an analysis can be adapted to a particular policy see J.E. Campos and S. Pradhan, (1997). In their article Campos and Pradhan attempt to develop a new approach whose emphasis is on examining how institutional arrangements governing the budget process affect incentives governing the allocation and use of resources. They define institutional arrangements, however, as rules, norms, and procedures both formal and informal.
} 
influence on the outcomes of the privatizations ${ }^{27}$, and many of the positive gains that should materialize after a privatization cannot be realised.

The weights given to the individual elements of the institutional framework will vary from policy to policy and programme to programme. When, for instance, analysing a programme to increase trade with a certain country, the weight assigned to the legal setting and the institutions enforcing laws in the countries concerned will be much more than when analysing education policies. For a trade programme, the exact definition of property rights and the protection of property rights by the government and its agencies are essential and should therefore be the subject of a scrutinized investigation before starting a trade programme. For an education policy, the investigation of the legal setting and law enforcing institutions will be less important and may warrant maybe only one paragraph in the analysis. Elements such as the social setting will carry much more weight in that case. The goal of this section is to identify the broad categories that should be taken into account when analysing a programme or policy - whether ex ante or ex post.

The element of the stakeholders of a policy also warrants the attention of evaluators and analysts. When designing, implementing and evaluating a policy, it is important to know who has what interest or stake in the implementation and/or outcome a policy (whether it be organizations or individuals or both ${ }^{28}$. The connections that exist among all those who have an interest in a policy should also be established as it may also influence the outcome of that policy. In order to gain insight into such interests and connections, it may be helpful to make a network chart in which all organizations and individuals and their interests and connections are represented graphically ${ }^{29}$. Conflicting interests of various organizations or individuals participating in a programme or policy do not necessarily mean those interests are incompatible or that they will have a negative influence on a policy or programme. Identifying all stakeholders and their interests means identifying a possible source of divergence from the expected outcomes of a policy and gives insight into the reasons why certain choices have been made.

\section{The institutional framework in international policies and programmes}

All elements of the institutional framework vary from one country to another. A policy or programme that was successful in one country may not be successful in another country on account of those variations. It is therefore important to establish, before implementing a policy or programme, what relevant differences exist in the institutional framework of two - or more countries and how that will influence the outcome of that policy or programme. To be able to do that, it is necessary that the policy maker is well aware of the exact institutional requirements of a policy and knows the institutional framework of the countries concerned very well. Without such knowledge it is not possible to assess the influence of (differences in) the institutional framework on a policy or programme.

Differences in the institutional framework between countries may be caused by the history of a country (think, for instance, of the communist legacy in transition countries as compared with the capitalist legacy in the USA and Western Europe), by the culture(s) of the people who inhabit a country, and by the geographical characteristics of a country: Is a country resource rich, and does it, for example, have access to the sea or not? Differences in the institutional framework can also be caused by stakeholders, who may have conflicting interests, and who may strive for power, influence, or other gains and may exert a decisive influence on the institutional framework of a country (stakeholders may, for instance, determine the political setting of a country, whether a

\footnotetext{
${ }^{27}$ One need only to look at the outcomes of the privatizations in the railway sector in Great Britain or the energy sector in the United States, let alone the results of the large-scale privatizations in the transition economies to see what may happen if certain premises are not fulfilled.

${ }^{28}$ The term 'stakeholders' is thus not limited to the target population of a policy measure.

${ }^{29}$ See Appendix 1 for an example of a network chart.
} 
country becomes a democracy or not, may determine which institutions get what power within the state, etcetera). The basic framework of analysis should be extended not only with the conceptual framework but also with the following elements (see Figure 5):

Figure 5: An extension of the basic framework: the institutional framework influenced by the elements history, culture and geography.

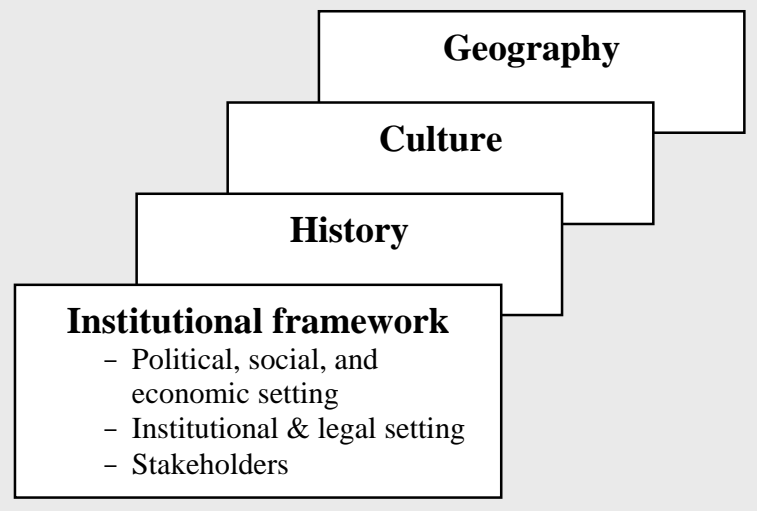

Herewith, the extended Geelhoed-Schouwstra framework is a rational model in which irrational or incremental elements are incorporated, thus giving those elements a place in evaluations. The schematic representation of the complete Geelhoed-Schouwstra framework of policy analysis now looks as follows (see Figure 6): 
Figure 6: The extended Geelhoed-Schouwstra framework of policy analysis

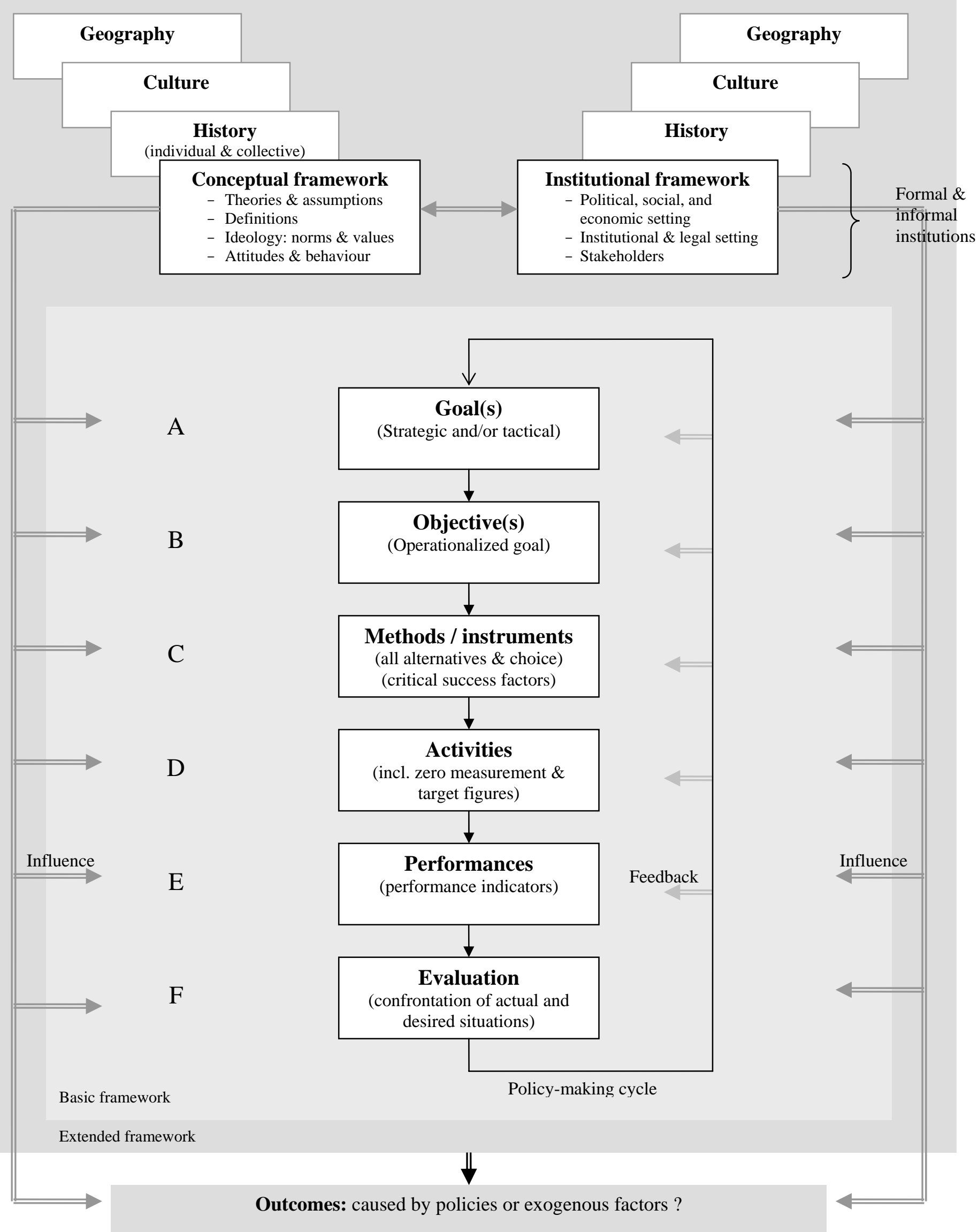




\section{Using the extended Geelhoed-Schouwstra framework}

\section{Using the extended Geelhoed-Schouwstra framework for policy making}

The extended framework can be used by policy makers as a method to make policies. If every step or element of the framework is conscientiously followed (i.e. from A to F), it will lead to a systematic process of policy making and a goal-oriented policy design. Making an overview of alternative methods or instruments in step $\mathrm{C}$ with all their pros and cons will furthermore guarantee a more rational and transparent decision-making process. With regard to the conceptual and institutional framework at every step in the policy-making process the policy maker has to establish: on which assumptions and theories his or her choices are based; what definitions he or she adheres to; and what the requirements of the policy or programme are with regard to the conceptual and institutional framework. If requirements are not compatible with the conceptual and/or institutional framework as it exists in a country, then the policy maker has to establish what influence this will have on the desired outcome of the policy, and how the undesirable effects of such incompatibility can be mitigated.

If the framework has been used well, evaluators will have the means to evaluate a policy or programme properly. With clearly stated goals, objectives, methods, instruments, critical success factors and activities accompanied by performance indicators, zero-measurement ${ }^{30}$, and target figures, the performances or outcomes of a policy ${ }^{31}$ can be evaluated. If the institutional requirements and assumptions, theories, and definitions ${ }^{32}$ have also been incorporated in a policy document, then it is possible to trace whether and why policies have or have not worked. Thus it is possible to make the policy process a learning process, in which improving the efficiency and effectiveness of policies and the improvement of accountability are central.

By giving evaluation its proper place and importance in the policy-making cycle, the learning process will be continuous. Automatic feedback will be generated on every element of the policy design at regular intervals in time (preferably in accordance with the cycle of planning and control of the organization concerned). Hence both policies and the policy-making process can be improved.

\section{An example of the use of the extended Geelhoed-Schouwstra framework for policy making}

With the advantage of hindsight I will give a brief example of how the extended framework of policy analysis can be used to design international policies while preventing undesired outcomes due to differences in conceptual and institutional frameworks of the country concerned and the international organization giving policy advice. In Mongolia in 1990 the process of transition from a communist to a market economy began. The international financial institutions (IFI) ${ }^{33}$ played an important role in this process and prescribed a speedy privatization and liberalization of the Mongolian economy. The goals of the IFI in Mongolia were to realize a market economy as fast as possible; to generate economic growth; and to establish macroeconomic stability. In agriculture all negdels (state farms and cooperatives) were to be privatized. For the privatization

\footnotetext{
${ }^{30}$ A zero-measurement is the initial measurement at the time of designing the policies.

${ }^{31}$ In Leeuw's (2003) terminology, the programme logic can be evaluated.

${ }^{32}$ In other words, the following questions need to be answered in the policy document: 'How is the policy/instrument/activity supposed to bring about the desired effect?' And 'What requirements need to be fulfilled with regard to the institutional framework for the policy to be effective and efficient?

${ }^{33}$ The international financial institutions are the International Monetary Fund (IMF) and the World Bank and all its branches.
} 
policy in agriculture, the basic framework of policy analysis could have been filled out at that time as follows ${ }^{34}$ (see Box I):

Box I: Mongolian privatization policy in agriculture:

an illustration of the use of the extended Geelhoed-Schouwstra framework for policy making

1) Create a market economy;

2) Generate economic growth (by increasing market-oriented production in agriculture).

\section{Goal:}

$\downarrow$

\section{Objective:}

1) Stimulate an increase in the production of animals and animal products in order to increase the food production and to increase the input in enterprises processing animal products quantitatively and qualitatively - so that they can in their turn increase the quantity and quality of their production.

\section{Method (all alternatives):}

a) Privatize (the herds of all) negdels (collectives and cooperatives) as fast as possible;

b) Privatize (the herds of all) negdels (collectives and cooperatives) gradually;

c) Turn collectives into cooperatives and give all members shares;

d) Try to increase production within the existing framework until the institutional and conceptual requirements for this policy are fulfilled, and then privatize the herds (either instantly or gradually);

e) Do not change the system at all but increase production within the system.

In this case none of the alternative methods were considered: the only method which was pursued was the immediate privatization of all herds:

\section{Method:}

1) Privatize (the herds of) all negdels (collectives and cooperatives) as fast as possible;

2) Allow the negdels great discretion to formulate their own rules for distributing the animals amongst their members and others who may hold claims on the animals;

3) Set a time limit within which the herds have to be privatized.

\section{Critical success factor(s):}

This category did not receive much attention when the policy was formulated.

Privatization of all herds within 1 year.

\section{Target figure(s):}

\section{Activities:}

1) Create a distributive code to assign animals to individuals;

2) Distribute animals to individuals;

3) Distribute assets (capital goods) of the negdels to individuals.

Zero-measurement(s):

1) $86 \%$ ?? of all animals were state-owned in 1990 .

\section{Performance indicator(s):}

1) Privatization of (all herds of) all negdels within 1 year.

\footnotetext{
${ }^{34}$ This example illustrates the bigger picture (with regard to the goals of the IMF and the national government of Mongolia) and the goals of this particular programme. By the way the framework of policy analysis is filled out, it is clear that it can be filled out in various ways. I have chosen the broadest view taking the goals according to the advice of the international organizations as a starting point. I could also have chosen the measure of privatization of the herds as the objective and fill out the framework from that starting point.
} 
This description is in accordance with the real privatization policy with regard to the herds in the early 1990s, just after the beginning of the transition to a democratic system and a market economy. At that time, the government had neither experience with market economies nor with non-communist methods of policy making. Thus it is not surprising that many elements that are usual in Western policy making have not been given much thought during the design of this policy. No thought was given to critical success factors, bottlenecks, and the institutional or conceptual requirements of the policy. Little thought had been given to planning, sequencing, and possible complementary policies. The old pattern continued of giving commands and expecting them to be followed (which indeed happened in this case). With regard to the critical success factors, four factors could have been formulated during the design even without any knowledge of necessary requirements with regard to the institutional and conceptual framework (see Box II):

Box II: Mongolian privatization policy in agriculture: Critical success factors

\section{Critical success factors:}

1) Allocate to each individual a sufficient number of animals so that they can breed and increase the number of animals;

2) Secure access to grazing grounds for all individuals who own animals (make a distributive code with regard to the grazing grounds. In Mongolia all grazing grounds are all publicly owned);

3) Secure access to the markets for all individuals so as to be able to buy and sell animals;

4) Secure access to veterinary services for all individuals.

Apart from those critical success factors, others will follow from the analysis of institutional and conceptual requirements. Starting with the institutional requirements and the institutional situation in Mongolia in the early 1990s (see Box III): What were the institutional requirements of the policy and how had the situation in Mongolia been at the time of the privatizations with regard to those requirements?

Box III: Mongolian privatization policy in agriculture: institutional requirements and institutional characteristics of Mongolia in the period 1990-1994

\section{Institutional requirements:}

1) Political setting: The political system should be reliable and facilitating;

2) Socio-economic setting / stakeholders: A good - honest and fair - distributive code is needed for allotting the animals to individuals;

3) Economic setting: A functioning market (both demand and supply are needed). There should be competition and thus choice;

\section{Institutional characteristics of Mongolia in} 1990-1994:

1) Political setting: The political system was in its infancy; facilitating but inexperienced, unfamiliar with market economies, and not yet reliable;

2) Socio-economic setting / stakeholders: Managers of the cooperatives and collectives had great discretion in determining the distributive code for their enterprise. This meant that the former managers came to own all assets (in the sense of capital goods) of the enterprises and that the distribution of the herds over individuals was uneven. Certain groups, such as elderly people, the handicapped, widows, and unmarried mothers with children were at a big disadvantage;

3) Economic setting: There were no markets yet and no competition; in the beginning the command economy still functioned; 
4) Economic setting: Prices should be liberalized;

5) Economic setting \& geographic characteristics: A marketing system is needed as well as a good - and preferably low-cost transportation system. When there are no persons who come to buy your animals (at the market price) and sell them at the market and you cannot reach the market yourself, then you have a problem;

6) Institutions: Institutions of mediation should exist in case of conflicts;

7) Institutions: Veterinary services should function and should be available for all herders;

8) Institutions: Money should be available for market transactions;

9) Legal setting: A proper legal system is a prerequisite;

10) Legal setting: A fair system of grazing rights should be established for all common ground.
4) Economic setting: In 1990 there were no liberalized prices yet, during the period 1990-94 many but not all prices were liberalized;

5) Economic setting \& geographic characteristics: In 1990 there still was the old communist marketing system, this was abolished before 1995 but not replaced by another functioning marketing system; costs of transportation were very high because of geographic characteristics;

6) Institutions: There were no institutions of mediation;

7) Institutions: The system of veterinary services provided by the state collapsed within a few years of the transition. It was not replaced by a new system because the herders lacked money (and possibly did not give it priority);

8) Institutions: Due to stringent macroeconomic policies (to attain macroeconomic stability) there was a shortage of money, especially in rural areas. This led to an extensive barter trade;

9) Legal setting: There was no proper legal system (there were neither functioning legal institutions nor the necessary rules for a market economy);

10) Legal setting: No rules were formulated as to who would be allowed to use what ground when grazing their herds.

The international financial institutions advised to the Mongolian government to privatize all stateowned assets (which included all animals) as soon as possible in order to create a market economy and to stimulate economic growth. What were the theories and assumptions underlying this advice? What were the ideas behind the formulated goals, objectives and methods? In Box IV below, the left column indicates the IFI's assumptions upon which they based their advice, as at that time the Mongolian government was at a loss as how to progress towards a market economy and followed any advice they could get (especially if it was accompanied by money). Thus, the theories and assumptions of the international institutions were the theories and assumptions underlying Mongolian policies at that time. The right column in box IV shows the situation with regard to the conceptual framework as it was in Mongolia during the privatizations.

Box IV: Mongolian privatization policy in agriculture:

The conceptual requirements and conceptual characteristics of Mongolia in 1990-1994

\section{Conceptual requirements:}

1) Theories \& assumptions: People will maximize output (as they will want to maximize their income which they can do with maximizing their output);

2) Theories \& assumptions: People will sell the surplus animals; they will ask market prices

\section{Conceptual characteristics of Mongolia in} 1990-1994:

1) Theories \& assumptions: People did maximize output: the number of animals increased from 25.5 million in 1991 to 29 million in 1996.

2) Theories \& assumptions: People did not sell their surplus animals. In the first years of the 
for them;

3) Theories \& assumptions: Enterprises will enjoy an increased input (due to optimizing herders selling of their surplus animals) both quantitatively and qualitatively and will automatically change to a market oriented production process, as otherwise there will be no demand for their products.

4) Theories \& assumptions: People want to acquire more wealth in terms of money (they are 'money-motivated').

5) Theories \& assumptions: Institutions will spring into existence automatically with privatizations and liberalization.

6) Attitudes and behaviour: With their own animals, herders will automatically display market economic thinking and behaviour;

7) Attitudes and behaviour: All children are sent to school. transition, the prices were still set by the Mongolian government and after that a marketing system no longer existed. Animals were still not sold at market prices. Herders only sold animals when they were in need of money or goods.

Norms and values: You do not kill (and sell off) animals unless you really have to;

3) Theories \& assumptions: Many animal processing enterprises experienced serious shortages in inputs. Many of them collapsed in the period after the privatizations and many of those that did survive did not change to marketoriented production processes in the first decade after the transition.

Foreign demand had collapsed anyway due to the collapse of Comecon; otherwise there was no foreign demand and there was no experience with foreign demand.

4) Theories \& assumptions: The Mongolians did want to acquire more wealth but not in terms of money. Instead they wanted it in terms of numbers of animals.

Norms \& values: A large herd was the sign of prosperity in Mongolia and not a lot of money.

5) Theories \& assumptions: Institutions did not spring into existence automatically and were lacking.

6) Attitudes and behaviour: Herders were - and are still - very government focussed. When there are problems, they expect the government to solve them. They do not take precautions such as making hay - to prevent calamities. They basically do not display real market economic behaviour ${ }^{35}$;

7) Attitudes and behaviour: If children are more useful or 'cheap' at home they are kept at home $^{36}$.

What were the results of the above-described privatization policy in Mongolia?

With regard to the activities and method, those were extremely successful. The negdels

established their own privatization codes - within the norms given by the Ministry - and all herds were privatized in a very short time and the assets of the negdels were in general also distributed to individuals. The objective of an increase in the number of animals was also reached.

\footnotetext{
${ }^{35}$ The herders accept the advantages of the market economy but do nothing to prevent the disadvantages ,for which they look to the government for assistance. The poor herders - those who do not have enough animals to breed or who are, for instance, struck by illness and death in the family - are not in a position to breed and display market economic behaviour. They have to fight for survival and have to sell off all their animals.

${ }^{36}$ This was actually a feature and a social side-effect that no one had foreseen: the drop-out rate of boys has increased enormously as a result of the privatizations as it was much more beneficial for families to have the boys tend animals (from about 9 years old). Girls , however, are still sent to school.
} 
The real objective, however, was to increase the input both quantitatively and qualitatively in animal processing enterprises. This objective was not reached. Neither was there an increase in, for instance, dairy production, which related to the first part of the objective (to increase food production). Animals were basically not sold by the herders. Why? What happened?

As can be seen in the overview of institutional requirements and characteristics of Mongolia, the institutions that are necessary to create an agricultural market economy were not there, thus creating a void. The idea that market institutions will automatically come into existence when the economy is being liberalized and privatized has proved to be wrong, just like the idea that people automatically display market economic behaviour in liberalized and privatized circumstances. The geographic characteristics of Mongolia - the vastness of the country in combination with a sparse population - also made the development of a market-oriented marketing system with low transport costs impossible as well as the development of a commercial veterinary service affordable for the herders. The absence of a low-cost and efficient transport system made dairy and other types of agricultural production virtually impossible. No thought had been given to the questions who should assert what grazing rights and when. The distribution of animals was disadvantageous to certain groups, who received too few animals to breed (and often lacked the knowledge of how to tend their animals, as they had held, for instance, administrative positions or had had a state pension). Together with the absence of a good marketing system, this created pressures on the grazing land closest to the village and city centres, which by now has resulted in extensive environmental damage. The institutional characteristics of Mongolia at the beginning of the transition were such that the stated objective was not attainable. The institutional requirements were too far from being fulfilled, a fact which had been overlooked by the international organizations as no systematic analysis had been made of the institutional requirements of the policy. This was not all, however. The factor that was, and still is, overlooked by the international institutions is the conceptual framework.

With regard to the conceptual framework, the assumptions underlying the policy advice of the IFI were different from the conceptual characteristics displayed in Mongolia at that time, as can be seen in the overview of the conceptual requirements and characteristics. Although crucial for the result of the policy, many assumptions of the advisors from the international organizations proved to be wrong. With their economic and often Western background, advisors assumed rationality of decisions in the sense of profit-maximizing behaviour. They also assumed that Mongolian herders would be money-motivated and would want to secure their lives in terms of having more money. Mongolian herders did indeed display rational behaviour, but of different kind than expected by the IFI advisors. The Mongolian herders tried to increase their herds as much as possible, as a big herd is the best insurance against calamities such as the $d z u d$ - a very harsh Mongolian winter which occurs at least once every decade. Even when half of the animals of the herd die during such a winter, a herder still has sufficient numbers to breed and increase the number of the herd again. Without a functioning insurance system - and without experience with such a system herders will rely on the old and tested ways of securing their livelihood, which is very rational. Moreover, from a pragmatic view, the herd was the best way to save wealth as inflation of the tugrik reached extremely high levels in the early 1990s (over 330\% in $1993^{37}$ ), whereas animals

\footnotetext{
${ }^{37}$ It was much more moderate in the following years but was still over 50\% in 1995 and 1996. In 1996 almost one third of inflation was accounted for by energy price adjustments as power and heating tariffs were raised by 60\%. See World Bank, Mongolia, Country Economic Memorandum, Policies for Faster Growth, Report No 16749-MOG, Washington D.C., 1997. p. vii; World Bank, Country Economic Memorandum, Priorities in Macroeconomic Management, report 13612-MOG, Washington, 1994, p.i.; ADB, Technical Assistance Performance Audit Report on Technical Assistance to the Banking Sector in Mongolia, TPA : MON 97028, 1997, p. 7, footnote 1; and ADB, Report and recommendation of the president to the board of directors on proposed loans and technical assistance grant to Mongolia for the financial sector program, November 1996, p.5.
} 
kept their value. It was thus a much more rational strategy to keep animals and to increase their numbers than to sell them. What the international advisors also did not know, and thus did not take into account in their advice, were the traditional Mongolian norms and values that recognize a large herd as the most important sign of wealth (and not money, thus reducing the incentive to sell animals for money), and nor were they aware that these norms and values go against the selling and killing of animals unless there is an urgent need to do so. Therefore, even if the institutional requirements had been fulfilled, it would have been doubtful whether the herders would have sold animals on a large scale just to make money. The Mongolian homo economicus obviously had a different rationality and other preferences than the foreign advisors had foreseen. The fact that there is more than one rationality was, and still is, not appreciated by international organizations who assume people to be a homo economicus in the sense of maximizing profit and wanting to earn as much money as possible.

What has become obvious when using this framework of analysis to design policies is that many institutional and conceptual requirements are actually prerequisites of a policy, potential bottlenecks, or critical success factors of a policy. Therefore, when this framework is being used, especially step C, the method(s) chosen, and the bottlenecks and critical success factors may change. These factors only become evident when one really looks into these factors specifically. In this example, it is also obvious that at that time the Mongolians did not work with zeromeasurements, target figures and performance indicators in the design of their policy. These deficiencies erode accountability and transparency of policies and diminish the orientation to the goals and objectives of a policy while increasing attention to the method. Finally, the most important point of this example is that it illustrates well how much is missed in searching for explanations for the success or failure of a policy if the conceptual and institutional frameworks are not taken into account.

Using the extended Geelhoed-Schouwstra framework for the evaluation of an international policy or programme

When the framework is used for analysing and evaluating policies and programmes, the framework provides a useful instrument to evaluate policies and programmes by systematically following all the steps of the policy-making cycle. With performance indicators, zeromeasurements, and target figures, the tools are provided to evaluate the performances of a policy or programme. The conceptual and the institutional framework provide good starting points for investigating how and why policies and programmes have brought about the ensuing results. Depending on the goal of the evaluation, the audience of the evaluation, and the background of the evaluator, different weights will be assigned to each individual element of the framework. Thus, accountants will only look at performance indicators in the basic framework. Institutional economists will attach more importance to elements of the institutional framework, whereas anthropologists will give more weight to the conceptual framework. The advantage of this framework is that it systematizes the policy-making process and identifies and brings together in a pragmatic way factors that play a role in shaping the outcomes of policies and programmes. An improvement over other models of policy making is that institutional and conceptual factors are taken into consideration.

To use the extended framework for analysing or evaluating international policies and programmes, it is not necessary that the policies concerned have actually been drawn up according to this framework. The importance of the framework lies is the fact that it systematizes policies and their analysis; it makes policies more transparent and increases attention for the conceptual and institutional frameworks of the policies, of both the country concerned and the international organizations and/or donor countries.

Using this framework for an analysis, one should first take all the steps of the basic framework in order to establish what a policy or programme is exactly about: a) What is the goal of the policy 
or programme? b) What are the objectives? c) What methods or instruments have been used?, etcetera. Once all the steps of the basic framework have been clarified, one should look systematically into the conceptual and institutional framework. The following questions should be addressed (see Box V):

Box V: Questions to analyse the institutional and conceptual framework systematically

1) What were the most fundamental requirements of the policy or programme with regard to the
institutional framework?
a. political setting
b. social setting
c. economic setting
d. institutions
e. legal setting
f. stakeholders
g. geographic characteristics

2) What were the most fundamental requirements of the policy or programme with regard to the conceptual framework?
a. theories and assumptions
b. definitions
c. ideology: norms \& values
d. attitudes and behaviour

3) How did the institutional framework of the country concerned look with regard to each of the fundamental requirements?

a. political setting

b. social setting, etc.

4) How did the conceptual framework of the country look with regard to the fundamental requirements?

a. theories and assumptions

b. definitions, etc.

5) Were all fundamental requirements with regard to the institutional and conceptual framework fulfilled in the country concerned? If not, how did this non-fulfilment influence the outcome of the policy or programme?

6) What measures have been taken or could have been taken to prevent undesired outcomes of the policy or programme?

To give an indication how an analysis of a programme can be made a brief description of an international project of Tempus TACIS, in which a curriculum change in medicine ${ }^{38}$ was planned at the National University of Mongolia (NUM), is provided. Obviously, the TACIS-model for the application of projects was used to design the project, and for the analysis the extended version of the Geelhoed-Schouwstra model was used (see Box VI).

Box VI: The example of a Tempus TACIS project: A curriculum change in medicine at the NUM

\footnotetext{
${ }^{38}$ Information on this project was gathered from interviews with the people involved in the project and from the article: B. Meyboom-de Jong and H.C.P.M. van Weert, 'Veranderingen in de medische opleiding in Mongolië’, Nederlands Tijdschrift voor Geneeskunde, number 149(29), 16 juli 2005, p. 1641-1645.
} 


\section{Goal(s):}

Train generalists who can provide basic healthcare in rural areas of Mongolia

(in $199780 \%$ of the doctors were specialist and only $20 \%$ generalists, whereas generalists were urgently needed, especially in rural areas).

\section{Objective(s):}

B Modernization (restructuring) of the medical curriculum in Mongolia.

C 1) Renewal of teaching practices;

2) Introduction of problem-based and integrated new curriculum suitable for training generalists;

3) Reintroduction of assistantships in rural areas (so that students get practical experience outside the academic or teaching hospital).

\section{Critical success factors:}

1) Sufficient English language skills of Mongolian teachers so that they can use English-language textbooks \& are able to follow the lectures of European teachers;

2) Sufficient English language skills of students so that they can learn from English-language textbooks.

\section{Possible bottlenecks:}

1) Lack of money;

2) No sum $^{39}$-hospitals equipped for assistantships;

3) Two ministries (i.e. Healthcare and Education) involved in renewal of medical curriculum.

\section{Activities:}

D 1) Train Mongolian teachers in modern pedagogic developments;

2) Train Mongolian teachers in multidisciplinary consultation;

3) Renew the library to equip it for self-study;

4) Create rural opportunities for medical students to acquire practical experience;

5) Create a formalized meeting structure for teachers of the NUM;

6) Create a department for curriculum (education) development at the medical faculty of the NUM.

\section{Zero-measurements:}

1) Neither clinical reasoning nor communications skills were taught at the university;

2) The only teaching form is classes (lectures for all students together, with a teacher in front of the class and the students taking notes)

3) No integration at all, neither between teachers nor between clinicians and pre-clinicians;

4) Due to a lack of money, no possibilities for practical experience outside the university hospital;

5) Only Russian textbooks; Marxist dialectics still part of the medical curriculum.

\section{Target figures:}

There was only one target figure which was not labelled as such: introduction of a new curriculum.

\section{Performances (performance indicator $=$ target figure):}

E

1) A balanced budget and corresponding payments and receipts;

2) Introduction of a new medical curriculum at the NUM.

\section{Evaluation: results}

1) The project succeeded in introducing a new medical curriculum at the NUM;

2) New teaching methods were introduced at the NUM and new exams (performance was tested)

3) Local (rural) training possibilities for students were created, and the medical library was improved;

4) Formalized meetings for teachers were created at the NUM, and cooperation and consultation was established among teachers (making an integrated approach of the new curriculum possible).

\footnotetext{
${ }^{39}$ The Sum is the smallest administrative unit in Mongolia (it is a locality).
} 
5) Department for medical curriculum development and coordination was created at the NUM.

In Box VI above the basic Geelhoed-Schouwstra framework has been filled out concisely for the TACIS-project. All fundamental information that is usually required for the application, approval and accountability of international projects and programmes - and their budgets - is mentioned. The fact that all information is given in a very limited space allows a good insight into a project at a glance. With regard to 'C-method' it should be remarked that in the course of an analysis the alternatives that have been considered - when known - should be mentioned and - again if known - what other alternatives could or should have been considered in the opinion of the evaluator. The latter information has not been included in the example.

What this basic analysis does not provide are the reasons why a project has achieved its goals or why it failed and what difficulties - that possibly might have been prevented had attention systematically been paid to the conceptual and institutional framework beforehand - the project encountered. For that, the requirements of the project with regard to the institutional and conceptual framework of the country concerned should be analysed as well as (when it is an ex post analysis) the problems that occurred with regard to the institutional and conceptual framework. With regard to the institutional framework, it is necessary to look systematically at the categories: a) political setting, b) social setting, c) economic setting, d) institutions, e) legal setting, f) stakeholders, and g) geographic characteristics; and with regard to the conceptual framework it is necessary to look at the categories: a) theories and assumptions, b) definitions, c) ideology: norms \& values, and d) attitudes and behaviour. Some characteristics or requirements can be categorized under more than one category. For the analysis it is not important under what category a requirement, characteristic or problem is classified, as long as it is classified somewhere and receives due attention. This example will not go into all requirements for all categories of this project because of space limitations, but the problems that this specific project encountered will be listed in order to demonstrate the importance of the institutional and conceptual framework for international projects, and why attention should be paid to them at the time a policy or programme is designed.

Before the project began the following institutional shortcomings had been noticed ${ }^{40}$ (see box VII):

Box VII: Institutional problems noticed before the start of the project

\section{Institutional problems:}

1) Institutions: Two Ministries needed to be involved in the curriculum development (which is likely to create problems of coordination, facilitation and approval by those Ministries): namely, the Ministry of Education and the Ministry of Health;

2) Institutions: The development of a new medical curriculum depends on the organization of the health sector in general. If that is not well organised, then neither can the curriculum be well organised (for instance in this case sum-hospitals were not equipped for clerkships).

3) Institutions/culture: The National University of Mongolia (NUM) needed to become more democratic; formalized meetings between teachers needed to be created; and a Department of Curriculum (educational) Development had to be created; a new organizational structure of the Faculty of Medicines of the NUM was a requirement for the success of the project ${ }^{41}$.

4) Geographic characteristics: the vastness of the country in combination with - very - scarce resources for

\footnotetext{
${ }^{40}$ This project was started at the request of the Medical Faculty of the National University of Mongolia. Before the project started, there had been a preparatory year in which these institutional problems came to the forefront.

${ }^{41}$ This problem can also be registered under conceptual problems as it is not only an organizational problem but also a problem of the internal culture of an organization.
} 
the health care system.

During the project, the following institutional shortcomings were registered (see box VIII):

Box VIII: Institutional shortcomings registered during the project:

\section{Institutional problems and/or developments:}

1) Institution (organization)/stakeholders: Teachers were paid by the number of contact hours with the students. New teaching methods meant a reduction in the number of contact hours with students and thus less payment to the teachers. With no change in the reward structure, this would ultimately lead to the dismissal of teachers. Thus the introduction of the new curriculum induced resistance among the teachers.

2) Stakeholders: students resisted changes in their curriculum, although it did not become obvious why that was the case.

3) Socio-economic setting: there were large-scale privatizations in the health sector, and a fee for services was introduced in the health sector in order to support a wider orientation and job description of doctors.

After the project, the following institutional problems were encountered (see box IX):

Box IX: Institutional problems encountered after the end of the project:

\section{Institutional problems:}

1) Institutions/pragmatic: As is usual in international projects, the duration of the project was 3 years. This time span is short for introducing a new curriculum for a study that takes at least 6 years of study and is too short to ensure that new practices and the new curriculum are really consolidated.

2) Social-economic setting/culture: The job-market in Mongolia is very fluid. Within a few years after the realization of the project, nearly all the people who had been involved in the project had moved to other jobs and other employers, taking with them all the knowledge that had been built up. Power political motives from higher-placed persons played a role in this.

With regard to 1 in Box IX, the period in which international projects are evaluated is generally too soon after the project to notice such structural phenomena. Usually evaluations are not done until two or three years after a project has been terminated. Thus, important information on factors influencing - the final results (success) of a project is lost. Furthermore, some characteristics in the conceptual and institutional framework of a country only become evident when a few projects have been evaluated, and when the results of those evaluations have been brought together in one analysis. In this case, the characteristic mentioned in Box IX number 2 is still not recognized as a general characteristic (and hence a problem) of the country. World Bank and ADB evaluations did notice this problem for capacity-building projects in Mongolian Ministries where the appointment of a new Secretary of State is usually accompanied by a change of personnel in at least all key positions. Because the IFI look only at their own programmes and projects, this particular feature is attributed to the political system. It is not yet recognized as a general problem for all international projects.

The conceptual framework hardly receives any attention at all, in both national and international policies and programmes, even though it may be crucial for the success of a project. In our example, no requirements with regard to the conceptual framework were registered prior to the project, but during the project some important conceptual constraints came to the forefront (see box X).

Box X: Conceptual problems encountered during the project: 


\section{Conceptual problems:}

1) Attitudes and behaviour: Mongolians do not voluntarily offer information. Unless asked, they will not share information with you. When asked, however, in general they answer all your questions frankly. This means that it is of crucial importance to ask the right questions. When you do not know what to ask, you have a big problem in your project.

2) Attitudes and behaviour: Mongolians also do not share information with each other. This means that, if you teach one person something, this knowledge remains with that person only and will not be shared with other people unless you tell or oblige them to do so.

3) Norm/theory: A change in the mindset of the teachers of the Medical Faculty was necessary so that they would take the clinical problems of the patient as the starting point of treatment.

5) Attitudes and behaviour: A change in the mindset of the teachers was necessary so that they could begin to cooperate and share information with each other.

In many national and international projects the budget has a central place in the planning of a policy or programme. The elements mentioned in the basic framework also receive attention, but the conceptual and institutional framework as such are not analysed and incorporated in policy and programme plans. As is obvious from the international project described above, those elements may be crucial to the (long-term) success of a project or programme.

\section{Using the extended Geelhoed-Schouwstra framework for a cross-country comparison}

When implementing the same policy or programme in various countries, it is usually not so much the differences in the elements of the basic framework which cause differences in outcomes but the differences in the conceptual and institutional frameworks that lead to differences in implementation, and thus in outcomes. The extended framework can be used to identify in a systematic way which elements cause differences in the outcome of the same programmes or policies between countries or organizations. With this information it is possible to first of all, establish what exactly the essential requirements of a policy or programme are with regard to the institutional and conceptual framework of a country. Hence, it can be established how a policy or programme should be adapted to a new country when it is implemented there. And second, problems with the institutional and conceptual framework of a country tend to occur in virtually all international programmes. Once it is established what those problems are, it is possible to take them into account to prevent negative side effects when starting new programmes and when redesigning current policies and programmes. The case of the medical curriculum reforms actually provides a good example of such a characteristic: the extreme mobility of individuals on the Mongolian job-market which prevents the development of expertise and human resources within an organization. Before starting projects on human resources development and building know-how within organizations, this problem should be tackled.

Using the extended framework of policy analysis for cross-country or cross-organization comparisons means systematically comparing each single element of the programme or policy of one country with the same element of that programme or policy of the other country with respect to all steps of the framework. First the elements of the basic framework should be compared to establish the exact goals, objectives, methods or instruments, critical success factors, activities including zero-measurements and target figures - and performance indicators. This is important as differences in the basic framework will, of course, lead to differences in outcome. The comparison of the basic framework of two countries can be represented schematically by Figure 7. 
Figure 7: A comparison of all elements of the basic framework for 2 countries or organizations.

$C S F=$ critical success factor $; 0$ measurement $=$ zero-measurement $;$ Perf. Indic. $=$ performance indicator.

\section{Country or organization A}

\section{Country or organization B}

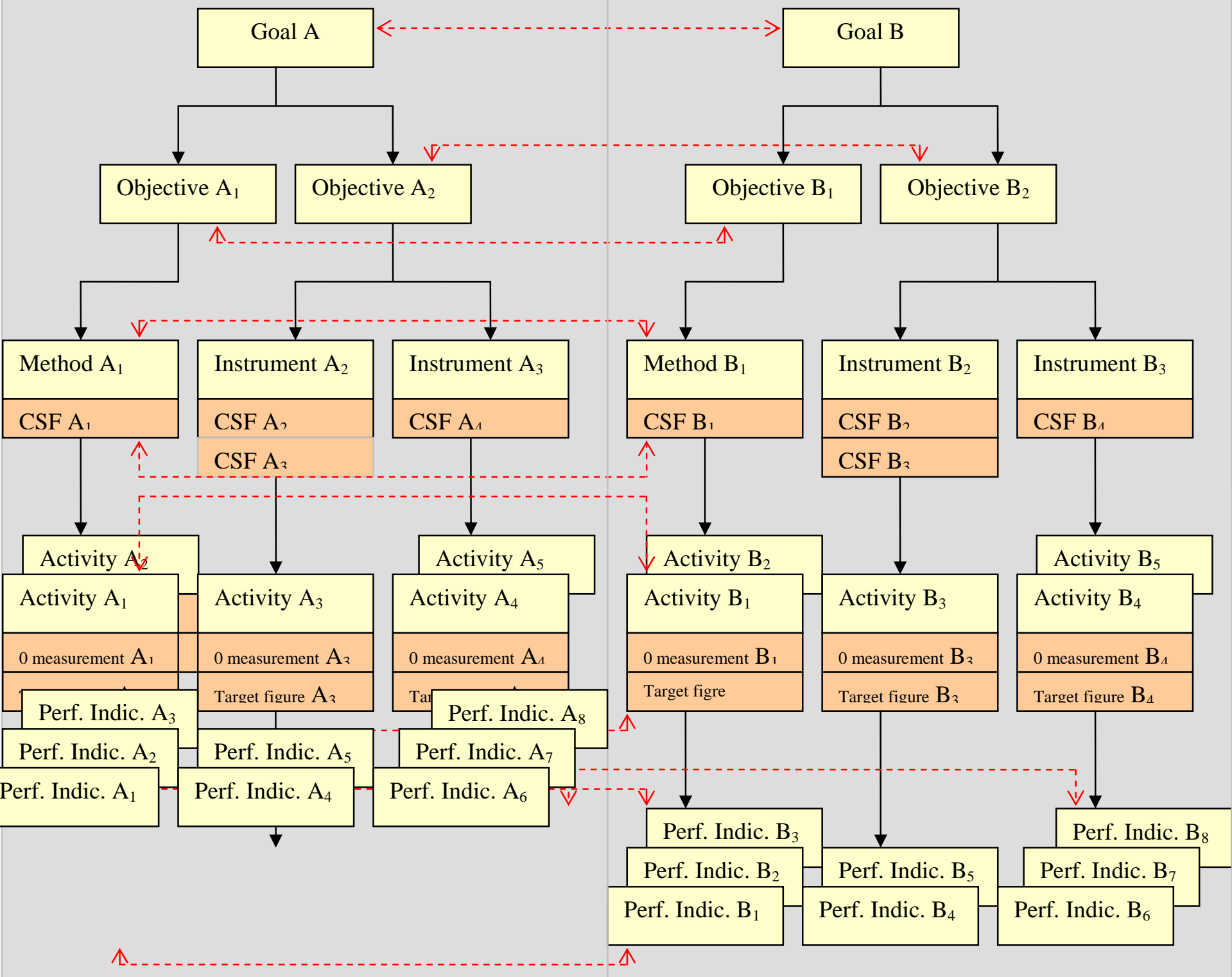

The goal of country $A$ is compared with the goal of that same policy or programme in country $B$. Objective $A_{1}$ of country $A$ is compared with objective $B_{1}$ of country $B$, and objective $A_{2}$ with objective $B_{2}$, method $A_{1}$ with method $B_{1}$, etcetera. Once all elements of the basic framework have been compared, the elements of the extended framework have to be compared. This is more complicated and more dependent upon the goal of the comparison or evaluation and on the evaluator. As written before, the weights assigned to the individual elements of the institutional framework - and hence the attention paid to each of the elements - are important for the comparison and may be important for the conclusions. 
When all elements of the basic framework have been established, it is then necessary to look into the extended part of the framework. First the fundamental requirements with regard to the conceptual and the institutional framework of the policy or programme should be determined.

Then the characteristics of the institutional and conceptual frameworks of the countries concerned should be compared with respect to all fundamental requirements in order to determine whether they are fulfilled or not and whether they are the same or different in the two countries. If the institutional or conceptual characteristics of the two countries (or organizations) are not similar, it should be established what the influence is, or may be (if the evaluation is done ex-ante), of these dissimilarities on the policy or programme, and how undesired outcomes can be prevented. This part of the analysis is schematically represented by box XI.

Box XI: Analysing the institutional and conceptual frameworks of countries to do a crosscountry comparison with regard to a policy or programme

1

\begin{tabular}{|c|c|}
\hline \multicolumn{2}{|c|}{$\begin{array}{l}\text { What are the most fundamental requirements of the policy or programme } \\
\text { to the institutional and the conceptual framework? } \\
\qquad \begin{array}{ll}1 . & \ldots \\
2 . & \ldots \\
3 . & \ldots\end{array}\end{array}$} \\
\hline $\begin{array}{c}\downarrow \\
\text { Country A: }\end{array}$ & $\begin{array}{l}\downarrow \\
\text { Country B: }\end{array}$ \\
\hline $\begin{array}{l}\text { How does the institutional framework look } \\
\text { with regard to each of the fundamental } \\
\text { requirements in country A? } \\
\text { a - political setting } \\
\text { b - social setting } \\
\text { c - economic setting } \\
\text { d - institutions } \\
\text { e - legal setting } \\
\text { f - stakeholders }\end{array}$ & $\begin{array}{l}\text { How does the institutional framework look } \\
\text { with regard to each of the fundamental } \\
\text { requirements in country } \mathbf{B} \text { ? } \\
\text { a - political setting } \\
\text { b - social setting } \\
\text { c - economic setting } \\
\text { d - institutions } \\
\text { e - legal setting } \\
\text { f - stakeholders }\end{array}$ \\
\hline
\end{tabular}

3

What are the institutional differences between country A and B?

\begin{tabular}{|l|l|}
\hline \\
\\
What are the most fundamental requirements of the policy or programme \\
to the institutional and the conceptual framework? \\
$\begin{array}{ll}\text { 1. } & \ldots \\
2 . & \cdots \\
3 . & \cdots\end{array}$ \\
\hline
\end{tabular}

How does the conceptual framework look with regard to the fundamental requirements in country $\mathbf{A}$ ?
How does the conceptual framework look with regard to the fundamental requirements in country $\mathbf{B}$ ? 


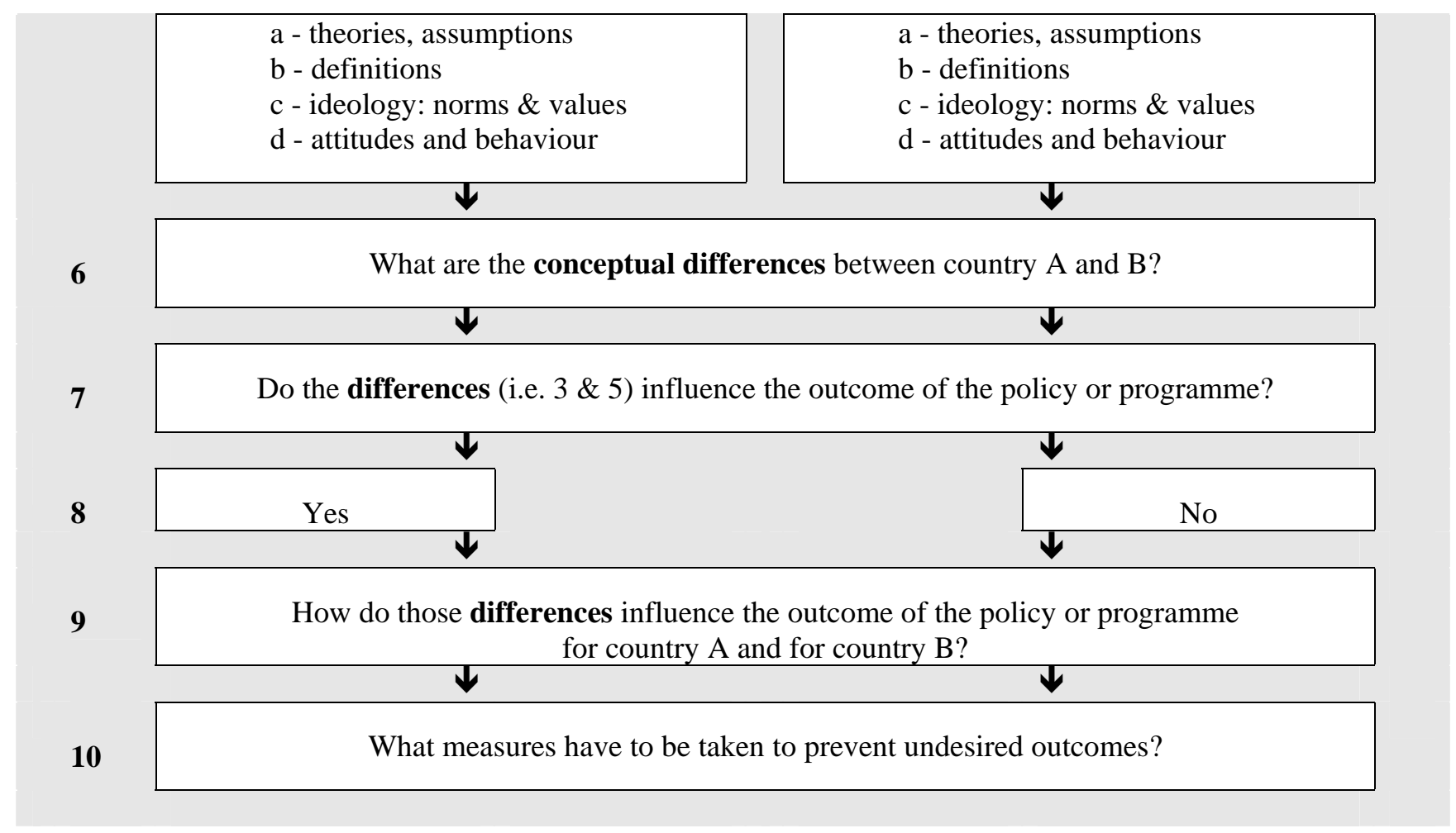

Using these templates for cross-country comparisons (both for ex ante and ex post analyses) would enhance the learning process in policy design and policy advice of international organizations, and might prevent costly mistakes due to differences in the conceptual and institutional frameworks of the countries concerned (or between international organizations and the countries concerned) or due to requirements in the institutional or conceptual framework that were not understood or diagnosed before a programme or policy started. When using Mongolia again as an example, it is obvious that geographic characteristics - the vastness of the country in combination with a sparse population - will influence all policies and programmes of the country, whether educational policies, health policies, financial policies or poverty alleviation programmes. Although the geographic facts are known by all, the consequences of these characteristics are often not well thought through. In public administration, the advice of international organizations was to decentralize many programmes and policies to a lower level of government - advice that makes sense given the vastness of the country. However, because of the sparse population and the fact that higher educational facilities and job possibilities are much better in Ulaan Baatar ${ }^{42}$ than in the provinces ${ }^{43}$, local administrations in general do not have the human resources (neither the capacity nor the capabilities and expertise) to design and implement their own policies and programmes, which may leave the country worse off if policy design is really delegated to those lower levels of government.

For international organizations that implement the same (kind of) programmes in various countries, a systematic comparison of the programmes according to the extended framework of policy analysis is particularly important. Seemingly minor differences between the institutional and conceptual frameworks of countries can cause large differences in the outcomes of policies and programmes. A common mistake that foreign advisors with experience in Asia make in Mongolia is to assume a 'collective' culture such as exists in for instance Korea and Japan. In Mongolia the culture is much more individualistic. Public goods are in general not cherished. The

\footnotetext{
${ }^{42}$ Ulaan Baatar is the capital of Mongolia.

${ }^{43}$ The provinces are normally called Aimags in the literature.
} 
common good is not given first priority by Mongolians, which leads them to have a different attitude and behaviour as compared with Koreans and Japanese. Thus, the outcomes of programmes and policies which implicitly assume such a 'collective' culture (and corresponding behaviour of individuals) will have a completely different impact and outcome in Mongolia than in Korea or Japan. When such differences are not recognized by foreign advisors, costly mistakes can easily be made - mistakes that could have been prevented had the differences been recognized in the stage of policy design when adequate policy measures could have been taken to prevent undesired outcomes of programmes and policies.

\section{Conclusion}

The Geelhoed-Schouwstra framework has been developed as a pragmatic instrument or tool to be used for designing and evaluating policies in order to improve upon the effectiveness and goalorientedness of a policy. The extended framework of policy analysis is an improvement over existing models of policy analysis as it gives attention in a systematic way to both institutional and conceptual (i.e. incremental) factors which influence the outcome of policies. This is important as policies and programmes do not always yield the desired or expected outcomes. With this framework it is possible to determine what factors caused the real-world policy outcomes to differ from the intended outcomes of a policy. Explanatory factors in the outcome of policies may be 'real world' factors such as badly-defined performance indicators or cyclical economic problems, or they may be inherent to the conceptual and institutional framework to which policy makers adhere.

The importance of this framework lies first of all in the fact that it identifies and systematically represents all elements that play a role in real-world policies without giving a weight - and thus value judgement - to the identified elements. Depending on the evaluator, the audience of the evaluation and the goal for which this framework is used, all elements in the framework can be given an individual weight. These weights will vary for each use and each user. Whereas accountants and many neo-liberal economists will give most weight to the basic framework, institutional economists will attach more importance to the institutional framework, and anthropologists and sociologists will tend to give more attention to the conceptual framework. Second, a model has been created with which evaluators can establish why a policy has, or has not, yielded the results expected from it. Third, the model can be used to compare the same policies and programmes in different countries - both in ex ante and ex post analyses- in order to identify what factors and what characteristics make a policy or programme successful and why a certain policy works in one country but does not work in another. When such factors and requirements with regard to the institutional and conceptual framework are established beforehand, costly mistakes may be prevented and tailor-made international programmes and policies for each individual country can be designed, thereby increasing the chance of success of a policy or programme. Fourth, a tool has been created that can be used in practice by national and international policy makers to improve the effectiveness of their policies by taking into consideration all elements that may exert a (possibly decisive) influence on their policies. The framework structures and systematizes the policy-making process, making it more transparent and facilitating more rational decision making. It improves the effectiveness of policies and makes policies more goal-oriented.

What is furthermore important is the place and importance of evaluations in the policy-making process. When evaluations are given their proper place in the policy-making cycle, policy making will become a continuous learning process in which automatic feedback is generated at certain intervals in time. Thereby policies can continuously be improved. The extended framework can be combined very well with models of planning and control within organizations, which adds to its usefulness. Thus managers can use it to define target figures and performance indicators with which they can steer the process more easily, thereby also improving the effectiveness of policies and programmes. 
Bibliography:

0 ADB, Report and recommendation of the president to the board of directors on proposed loans and technical assistance grant to Mongolia for the financial sector program, November 1996

- ADB, Technical Assistance Performance Audit Report on Technical Assistance to the Banking Sector in Mongolia, TPA : MON 97028, 1997

o Bamberger, M., 'The Evaluation of International Development Programs: A View from the Front', American Journal of Evaluation, 21(1), 2000, pp. 95-102.

o Campos, J.E., Pradhan, S., 'Evaluating Public Expenditure Management Systems: An Experimental Methodology with an Application to the Australia and New Zealand Reforms', Journal of Policy Analysis and Management, 16(3), 1997, pp. 423-445.

o Daft, R.L., Organization Theory and Design, $7^{\text {th }}$ edition, Cincinnati, Ohio, 2001.

o Driver, M.J., Brousseau, K.R., Hunsaker, P.L., The dynamic decisionmaker, Five Decision Styles for Executive and Business Success, Grand Rapids, 1990.

o Geelhoed, J., Control Deficiencies in the Dutch Health Care Sector, An analysis of the planning and control cycle in hospitals and the Dutch Ministry of Health and the relationship between them, Enschede, 2005.

o Geelhoed, J. and Schouwstra, M., "Krachtige overheid begint met heldere taal”, Openbaar Bestuur, nr 8, August 2005, pp. 2-5.

o Grasso, P.G., 'What Makes an Evaluation Useful? Reflections from Experience in Large Organizations', American Journal of Evaluation, 24(4), 2003, pp. 507-514.

o Hitch, C.J., and McKear, R.N., The economics of defence in the nuclear age, 1960.

o Inter ministerial Consultations for Financial and Economic Affairs, Policy Budgets and Policy Accountability: Evaluation, Lessons from practice, December 2004, paragraph 1.1; as to be found on the website of the Dutch Ministry of Finance (www.minfin.nl): http://www.minfin.nl/default.asp?CMS_ITEM=MFCWD5B4F2282C7A04D2C9A771A8 FFCDBFDDFX2X43972X65

o Lawrence Neumann, W., Basics of Social Research, Boston, 2004.

o Leeuw, F.L., 'Policy theories, knowledge utilization, and evaluation', Knowledge \& Policy, 91(4), 1991, pp. 73-92.

o Leeuw, F.L., 'Reconstructing Program Theories: Methods Available and Problems to be solved', American Journal of Evaluation, 24 (1), 2003, pp.5-20.

o Meyboom-de Jong, B., and van Weert, H.C.P.M., 'Veranderingen in de medische opleiding in Mongolië’, Nederlands Tijdschrift voor Geneeskunde, nr. 149 (29), 16 juli 2005, pp. 1641-1645. 
o Ministerie van Financiën, VBTB, Van Beleidsbegroting tot Beleidsverantwoording, Den Haag, May 2002, as found on the website of the Dutch Ministry of Finance (www.minfin.nl): http://www.minfin.nl/default.asp?CMS ITEM=MFCWD07140A91790B4901A372B8B $\underline{\text { ECE1A696BX2X36817X76 }}$

o Mosse, D., 'Is Good Policy Unimplementable? Reflections on the Ethnography of Aid Policy and Practice', Development and Change 35(4), 2004, pp. 639-671.

o Nove, A., 'The problem of "success indicators” in Soviet industry', Economica, 25(97) (Feb. 1958), pp. 1-13.

o Van Oirsouw, R., Spaanderman, J., and De Vries, H., Informatie economie, Meppel, 1993.

o Pitz, F.P., McKillip, J., Decision analysis for program evaluators, Beverly Hills, 1984

o Prayukvong, W., A Buddhist economic approach to the development of community enterprises: a case study from Southern Thailand, Cambridge Journal of Economics, 29, 2005, pp. 1171-1185.

o Rogers, P.J., Hacsi, T.A., Petrosino, A., Huebner, T.A., Program Theory in Evaluation: Challenges and Opportunities, New Directions for Evalution, no.87, San Fransisco, 2000

o Rossi, H.R., Lipsey, M.W., Freeman, H.E., Evaluation, A Systematic Approach, $7^{\text {th }}$ edition, Thousand Oaks, 2004.

o Russ-eft, D., Preskill, H., Evaluation in organizations, a systematic approach to enhancing learning, performance, and change, Cambridge, 2001

o Rossi, P.H., Freeman, H.E., Evaluation, A Systematic Approach, $4^{\text {th }}$ edition, Newbury Park (California), 1989

o Stufflebeam, D.L., 'A Note on the Purposes, Development, and Applicability of the Joint Committee Evaluation Standards', the American Journal of Evaluation, 25(1), Spring 2004, pp. 99-102.

o World Bank, Country Economic Memorandum, Priorities in Macroeconomic Management, report 13612-MOG, Washington, 1994

o World Bank, Mongolia, Country Economic Memorandum, Policies for Faster Growth, Report No 16749-MOG, Washington D.C., 1997

Websites consulted for this article:

o www.adb.org

$0 \quad$ www.ideas-int.org

o www.imf.org

o www.minfin.nl

o www.worldbank.org 


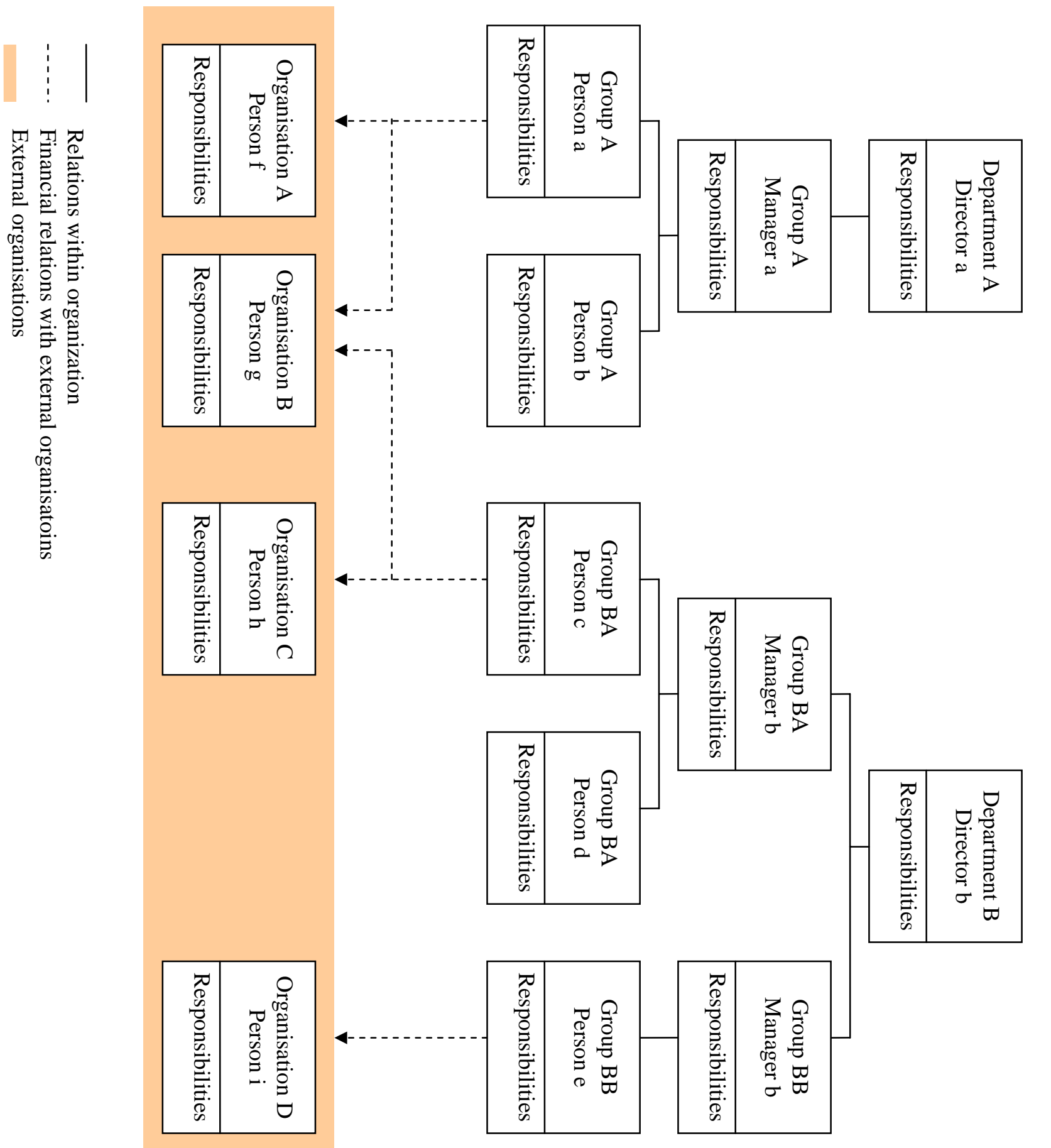

Appendix 1: network chart

In a network chart all those involved in a project are schematically represented, together with the relations between all parts of the organization and/or between the persons. Both formal and informal relations can be included in the scheme. Furthermore, for each person, his or her function and his or her responsibilities or tasks or financial resources may be included in the scheme. One can, furthermore, indicate whether a person supports a policy or change in policy, a neutral towards the subject concerned or is negative about it. 